\title{
Observational evidence of a negative biodiversity-stability relationship in intertidal epibenthic communities
}

\author{
Nelson Valdivia ${ }^{*}$, Markus Molis \\ Biologische Anstalt Helgoland, Alfred Wegener Institute for Polar and Marine Research, Section Seaweed Biology, \\ Kurpromenade 201, 27498 Helgoland, Germany
}

\begin{abstract}
The idea that diversity begets the functioning and stability of ecosystems has been intensely examined in terrestrial habitats, yet these relationships remain poorly studied in the marine realm. Theoretical and empirical work suggest that diversity enhances the stability of communities, but decreases the stability of populations. This is because compensatory dynamics, such as when one species decreases while another increases, stabilise the community as long as species richness increases the variety of responses to the environment. In an observational field study, the temporal variability in species abundance was used as a measure of stability that was compared among 5 intertidal sites of naturally different species richness. Percent coverage of macrobenthic species was estimated every 6 mo for 2 yr. Stability in total community coverage was a negative but curvilinear function of species richness. In addition, the stability of single populations (averaged over all species) fluctuated across the species richness gradient, without showing the predicted negative pattern. We found no evidence for increasing compensatory dynamics with increasing species richness, suggesting that the variety of responses to environmental changes was unrelated to diversity. Diversity-stability relationships in natural communities may be more complex than those predicted by theory and manipulative experiments.
\end{abstract}

KEY WORDS: Diversity-stability hypothesis $\cdot$ Hard bottom $\cdot$ Intertidal $\cdot$ Marine $\cdot$ Portfolio effect Species compensation $\cdot$ Species richness $\cdot$ Statistical averaging $\cdot$ Temporal variability

\section{INTRODUCTION}

The effects of biodiversity on ecosystem processes have received considerable attention because of the concern that loss of biodiversity can impair the functioning of ecosystems (reviewed by Hooper et al. 2005, Stachowicz et al. 2007). Greater species diversity represents more adaptive responses to environmental fluctuations (MacArthur 1955, Elton 1958). By this, the probability that some species maintain functioning when other species fail ensures the persistence of ecosystem properties under variable environmental conditions (Walker 1992, Yachi \& Loreau 1999). Indeed, influential research in terrestrial habitats has shown that diversity is beneficial for the functioning and stability of ecosystems (e.g. Tilman 1996, Hector et al.
1999, Loreau \& Hector 2001, Tilman et al. 2006). These ideas, however, remain poorly examined in aquatic ecosystems, for which there is also a need to understand the ecological consequences of species loss (Gessner et al. 2004, Hooper et al. 2005). Considering the differences between terrestrial and aquatic ecosystems (Giller et al. 2004), generalisations obtained from terrestrial habitats may not apply to marine habitats.

Stability has several meanings in ecology, including the resistance to and the resilience from disturbances, the resistance to invasions, and the temporal variability in a community property (Johnson et al. 1996, Shea \& Chesson 2002). In the present study, we focus on temporal variability, expressed as the temporal variance in total species coverage of intertidal epibenthic communities, and on the role of statistical averaging (also 
called the portfolio effect) and overyielding as 2 mechanisms by which community variability decreases with increasing diversity. Statistical averaging occurs when an aggregate community property (e.g. total community abundance) is calculated by adding that property across species. If the temporal variations of species are asynchronous, adding more species will increase the probability that those fluctuations are averaged out and the variability in total abundance will decrease merely on statistical grounds (Doak et al. 1998). Nevertheless, because asynchrony among species can result from the different abilities of species to tolerate environmental changes, statistical averaging is due, in part, to ecological differences among species (Cottingham et al. 2001).

Asynchrony in species fluctuations leads to compensatory dynamics, such that the abundance of one species decreases while that of another increases; the resulting negative covariance buffers the community stability (e.g. Vasseur \& Gaedke 2007). If species richness increases the variety of responses to the environment, then the presence of more species increases the probability that some species will compensate for the loss of others (Yachi \& Loreau 1999, Ives et al. 2000). Increasing compensatory dynamics with increasing diversity will tend to stabilise the community, but will cause individual populations to be more unstable (Lehman \& Tilman 2000).

The strength of statistical averaging effects depends on the relative abundance of species (Steiner et al. 2005). When species contribute unequally to the community abundance, the negative effect of diversity on community variability is dampened (Doak et al. 1998), as shown in terrestrial plant communities (Polley et al. 2007). Moreover, high species dominance can lead to negative and non-linear diversity-stability relationships (Lhomme \& Winkel 2002).

Overyielding, increases in the mean of an aggregate property with species richness, is the second mechanism that influences the diversity-stability relationship. Overyielding comes from differences among species-if many species compete for several resources, then coexistence results in a greater proportion of space covered by the community (Tilman et al. 1997). A more diverse assemblage stands for greater variety of species traits, which can cause the average community property to increase in comparison to the property of the average population. This overyielding effect will temporally stabilise the community as species richness increases (Lehman \& Tilman 2000).

Experimental manipulation of marine epibenthic diversity shows that diversity enhances community stability (reviewed by Stachowicz et al. 2007). Spatial models based on observational data, however, predict the contrary (Dunstan \& Johnson 2004, 2006). This is possible when species produce aggregate structures (e.g. aggregations of conspecifics or colonies), as a result of differential use of the space among species. These structures raise spatial refuges, leading to enhanced probabilities of survival and to more stable communities at low-diversity sites (Dunstan \& Johnson 2004, 2006). Contrarily, theory predicting a positive diversity-stability relationship is based on the assumption of well-mixed communities, where aggregations of conspecifics are almost absent (Dunstan \& Johnson 2006).

In an observational study, we tested the relationships between species richness and community stability. Observational studies permit the inspection of broader ranges of species richness and more realistic environmental conditions than those usually present in manipulative experiments (Stachowicz et al. 2007). We tested whether species richness is positively related to community stability (temporal variability in coverage summed across all species in a sampling unit), but negatively related to population stability (temporal variability in the coverage of individual epibenthic species). In addition, we investigated whether species richness is positively related to average community coverage (i.e. overyielding effect), and whether species richness is positively related to the occurrence of species compensation (i.e. whether species covariances become more negative as species richness increases).

\section{MATERIALS AND METHODS}

Study sites. The study was conducted at 5 intertidal sites of naturally differing species richness on the rocky shore of Helgoland Island, NE Atlantic. Each site was ca. $200 \mathrm{~m}^{2}$ in area, and adjacent sites were $\geq 100 \mathrm{~m}$ apart from each other. Two sites, 'barren ground' (BG) and 'semi-sheltered Fucus bed' (SFB), were located on the moderately exposed north-eastern shore, which is partly sheltered from wave action by a $250 \mathrm{~m}$ long concrete jetty running from north to south. The mid-intertidal at BG was formerly dominated by the blue mussel Mytilus edulis and fucoid seaweeds (Bartsch \& Tittley 2004). Today, the community at BG is dominated by the encrusting coralline algae Phymatolithon spp. and high densities of the periwinkle Littorina littorea, while mussels and fucoid seaweeds have almost disappeared. During September and November 2007, the average densities of $L$. littorea were 227 and 281 ind. $\mathrm{m}^{-2}$ at BG, but 16 and 90 ind. $\mathrm{m}^{-2}$ at SFB (M. Molis unpubl. data). At SFB, the canopy-forming brown seaweed Fucus serratus extensively covers the substrate from the lower intertidal to the upper subtidal, where the understorey is dominated by Phymatolithon spp. and the turf-forming algae Cladophora rupestris, 
Chondrus crispus, and Corallina officinalis (Bartsch \& Tittley 2004). The third site, 'exposed Fucus bed' (EFB) was located at the western wave-exposed rocky shore of Helgoland. Here, the dense F. serratus canopy has been gradually replaced by the red algae $C$. crispus and Mastocarpus stellatus (Bartsch \& Tittley 2004). The fourth and fifth sites were located on concrete harbour walls in the south-eastern area of Helgoland. 'Exposed mole' (EM) is a wave-exposed site, dominated by dense turfs of $C$. rupestris, patches of the barnacle Verruca stroemia, and Phymatolithon spp. The fifth site, 'sheltered harbour' (SH) is a wave-sheltered site dominated by a number of red algae such as Phyllophora spp., Ceramium virgatum, and Bonnemaisonia hamifera (Trailliella-phase). In addition F. serratus and the encrusting bryozoan Electra pilosa exist here in high abundance.

Community sampling. During March 2006, fifteen $0.5 \times 0.5 \mathrm{~m}$ plots were randomly positioned and permanently marked with stainless steel screws at each site. All sites were sampled every 6 mo between March 2006 and March 2008, except that the final sampling of $\mathrm{SH}$ was delayed by 1 mo. Due to time constrains, a random sub-sample of 9 fixed plots was followed throughout time. In species accumulation curves, 7 or 8 plots were enough to represent the number of species at each site (Appendix 1, Supplementary Material available at http://www.int-res.com/articles/suppl/b004 p263_app.pdf). Over the 2 yr study period, 2 plots were lost at $\mathrm{SH}$ and EFB, and 1 plot, at EM.

For each plot, percent coverage of each macrobenthic species was estimated to the nearest $1 \%$. Species with $<1 \%$ coverage in a plot were uniformly recorded with $0.5 \%$ abundance. Due to the multilayered structure of the assemblages, total community coverage could well exceed $100 \%$. Taxa were identified to the lowest possible taxonomic level in the field. For ambiguous taxa, sub-samples collected from adjacent areas were identified in the laboratory. Some taxa were identified to genus level, such as Phymatolithon spp., Porphyra sp. and Ulva spp. Small burrowing spionids were classified as the family Spionidae and small filamentous brown algae as order Ectocarpales (Appendix 2, Supplementary Material available at http://www.int-res.com/articles/suppl/b004p263_app. pdf).

Data analysis. Because species richness did vary over time, the gradient of species richness was defined by using species accumulation curves that were generated separately for each site, using the data for all sample dates. The maximum number of species obtained from each curve corresponded to the site-specific richness used in the analyses. Species occurring in $<3$ out of the 5 sample dates or contributing $<1 \%$ to total community coverage were omitted from all analyses, except for rare species with a consistent seasonal pattern (defined as the occurrence of a species during the same season across years).

The PRIMER similarity-percentages routine, SIMPER, was used to identify the species with larger contribution to the multivariate structure of each site. Bray-Curtis (BC) similarities (1 - BC) were calculated between all pairs of samples in the entire data set. The average similarities between all pairs of within-site samples were then broken down into separate contributions from each species to the structure of each site (Clarke \& Warwick 2001).

The $\mu \sigma^{-1}$ ratio (temporal stability, $S$ ) was used as a measure of community stability, where $\mu$ is the temporal mean community total coverage for a time period and $\sigma$ is its temporal standard deviation over the same interval (Tilman 1999). In comparison to the frequently used coefficient of variation $\left(100 \sigma \mu^{-1}\right)$, which approaches zero as stability increases, $S$ is advantageous because its magnitude increases with stability. The stability of the $i$ th species, $S_{i}$, was calculated by dividing its mean coverage by its standard deviation. Population stability was then calculated for each plot by averaging $S_{i}$ across all species (Tilman et al. 2006).

The temporal variance in total community coverage was partitioned into the sum of all $(N)$ species variances and covariances. This was done by calculating an $N \times N$ covariance matrix across time for each plot; the sum of all values in the diagonal corresponds to the summed species variances, and the sum of the off diagonals to the summed species covariances. The sum of the full covariance matrix corresponds to the net variance (i.e. summed variances plus summed covariances). The summed covariances were used as a measure of compensatory dynamics - if species compensation increases, then the summed covariances become more negative.

Regression analyses of the relationship between diversity and stability were conducted using R environment, Version 2.7.2 (R Development Core Team 2008). We conducted orthogonal polynomial regressions to assess curvilinear patterns of diversity-stability relationships. We tested up to the fourth-order fit (1 minus the number of richness levels), and we used the procedure described by Sokal \& Rohlf (1995), in which the significance of each polynomial regression is tested as part of the ANOVA table. All curves were fitted using least-squares regression, and ANOVAs were applied using the general linear model routines. All measures of stability were $\ln$ transformed due to their patchy statistical distribution. The transformation assured normality and allowed the use of general linear models.

Regression analyses were also used to investigate the relationship between richness and (1) the average 
total community coverage (averaged over the 5 sample dates), (2) the sum of all species variances, (3) the sum of all pair-wise species covariances, and (4) the net variance in total community coverage. Analysis 1 was done to test whether increasing species richness leads to overyielding, and Analyses 2, 3 and 4 were done to test whether increases in the variance of species abundances are offset by increasingly negative species covariances.

Statistical averaging effects depend on the way in which the temporal variance in the abundance of a species changes with the temporal mean (Tilman et al. 1998). The general tendency of the variance $\sigma^{2}$ to increase with the mean $\mu$ is described with Taylor's power function, $\sigma^{2}=c \mu^{z}$, where $c$ is a constant and $z$ is the scaling coefficient (Taylor 1961). The value of $z$ affects the strength of the statistical averaging, with $1<z<2$ meaning that diversity dampens the community variability but increases the population variability (Tilman et al. 1998, Tilman 1999). The logarithmic transformation of $\sigma^{2}=c \mu^{z}$ results in a linear equation in the form of $\log \left(\sigma^{2}\right)=c+z \log (\mu)$. We fitted this regression to the most important species identified by SIMPER routines and to the entire data set, combining all species.

\section{RESULTS}

Seventy-three taxa were identified during the study; 52 were included in the analyses (Appendix 2). Site-specific species richness was 30 at BG, 34 at EFB, 36 at EM, 40 at SFB, and 43 at SH. The total community coverage averaged over the 5 sample dates $( \pm$ SEM) ranged from $119 \pm$ $7 \%$ (BG) to $211 \pm 6 \%$ (SFB). The taxa contributing most to the community structure at each site were identified using SIMPER routines (Table 1). At BG, EM, and SFB, 3 to 4 species contributed $90 \%$ to the communities; at EFB and SH, 6 and 8 species, respectively. The taxa with the highest and most consistent contributions to withinsite similarities were Phymatolithon spp., Fucus serratus, and Cladophora rupestris (Table 1). These 3 species represented $61 \%$ of the sum of all species abundances from the 5 sample sites.

Contrary to our predictions, community stability was a negative and curvilinear function of species richness (Fig. 1). Accordingly, both the linear and cubic models fit these data significantly (Fig. 1,
Table 2). Highest community stability values were found at BG, while lowest values were found at EFB and $\mathrm{SH}$. Population stability showed large fluctuations over the species richness gradient, and no clear trend of decreasing values was observed. Consequently, the linear model was insignificant, whereas the quadratic and quartic models explained significant portions of the population stability data (Fig. 1, Table 2). Population stability was highest at EM, and lowest at EFB and $\mathrm{SH}$.

The average total community coverage significantly increased with site-specific species richness $(y=-54.10+$ $\left.5.95 x, \mathrm{R}^{2}=0.5, F_{1,38}=38, \mathrm{p}<0.0001\right)$. In addition, total community coverage increased with site diversity at each of the sample dates (separate regressions performed at each sample date, $\mathrm{p} \leq 0.004)$.

The summed variances showed an oscillating pattern across the species richness gradient and a signifi-

Table 1. Dominant taxa at sites with naturally differing numbers of species. Decomposition of within-site Bray-Curtis similarities into contribution of taxa to the structure of each site $\left(\right.$ Contribution $\left._{i}\right)$. Contributions of taxa are also expressed as percent $\left(\%_{i}\right)$. A value of the ratio Contribution ${ }_{i} / \mathrm{SD} \geq 1 \mathrm{in}-$ dicates that the contribution of taxon $i$ to the within-site similarity is consistent across all pairs of samples. Percent coverage (averaged over plots and all sample dates) of each taxon is given (\% coverage $\left.e_{i}\right)$. Site-specific species richness is given in brackets. Taxa cumulating up to $90 \%$ of the contribution to the within-site similarities are shown

\begin{tabular}{|c|c|c|c|c|}
\hline Taxon & $\begin{array}{c}\% \\
\text { coverage }_{i}\end{array}$ & $\begin{array}{l}\text { Contri- } \\
\text { bution }_{i}\end{array}$ & $\%_{i}$ & $\begin{array}{c}\text { Contribu- } \\
\text { tion }_{i} / \mathrm{SD}\end{array}$ \\
\hline \multicolumn{5}{|l|}{ BG, barren ground (30) } \\
\hline Phymatolithon spp. & 70.78 & 49.31 & 78.90 & 2.95 \\
\hline Littorina littorea & 6.67 & 3.96 & 6.33 & 1.92 \\
\hline Hildenbrandia rubra & 7.92 & 2.62 & 4.19 & 0.56 \\
\hline Haemescharia hennedyi & 12.32 & 2.56 & 4.09 & 0.31 \\
\hline \multicolumn{5}{|c|}{ EFB, exposed Fucus bed (34) } \\
\hline Phymatolithon spp. & 42.67 & 16.13 & 40.35 & 1.27 \\
\hline Fucus serratus & 32.37 & 9.08 & 22.71 & 0.75 \\
\hline Chondrus crispus & 17.89 & 5.27 & 13.19 & 0.81 \\
\hline Corallina officinalis & 8.63 & 2.09 & 5.23 & 0.61 \\
\hline Mastocarpus stellatus & 9.24 & 1.96 & 4.91 & 0.50 \\
\hline Ulva spp. & 11.66 & 1.70 & 4.26 & 0.38 \\
\hline \multicolumn{5}{|l|}{ EM, exposed mole (36) } \\
\hline Cladophora rupestris & 86.68 & 49.02 & 73.15 & 3.10 \\
\hline Phymatolithon spp. & 20.56 & 6.28 & 9.37 & 1.07 \\
\hline Verruca stroemia & 22.75 & 5.88 & 8.78 & 0.94 \\
\hline \multicolumn{5}{|c|}{ SFB, semi-sheltered Fucus bed (40) } \\
\hline Fucus serratus & 76.27 & 29.30 & 40.33 & 2.43 \\
\hline Phymatolithon spp. & 66.51 & 26.89 & 37.02 & 3.69 \\
\hline Cladophora rupestris & 38.40 & 12.52 & 17.24 & 1.96 \\
\hline \multicolumn{5}{|l|}{ SH, sheltered harbour (43) } \\
\hline Ceramium virgatum & 31.79 & 7.63 & 23.60 & 0.67 \\
\hline Fucus serratus & 30.69 & 6.24 & 19.28 & 0.59 \\
\hline Electra pilosa & 22.29 & 4.85 & 15.00 & 0.73 \\
\hline Bonnemaisonia hamifera & 23.57 & 4.03 & 12.47 & 0.39 \\
\hline Phyllophora spp. & 12.14 & 2.34 & 7.24 & 0.62 \\
\hline Chondrus crispus & 9.97 & 2.31 & 7.13 & 0.73 \\
\hline Ulva spp. & 8.87 & 1.30 & 4.02 & 0.56 \\
\hline Ectocarpales & 10.81 & 1.14 & 3.53 & 0.31 \\
\hline
\end{tabular}




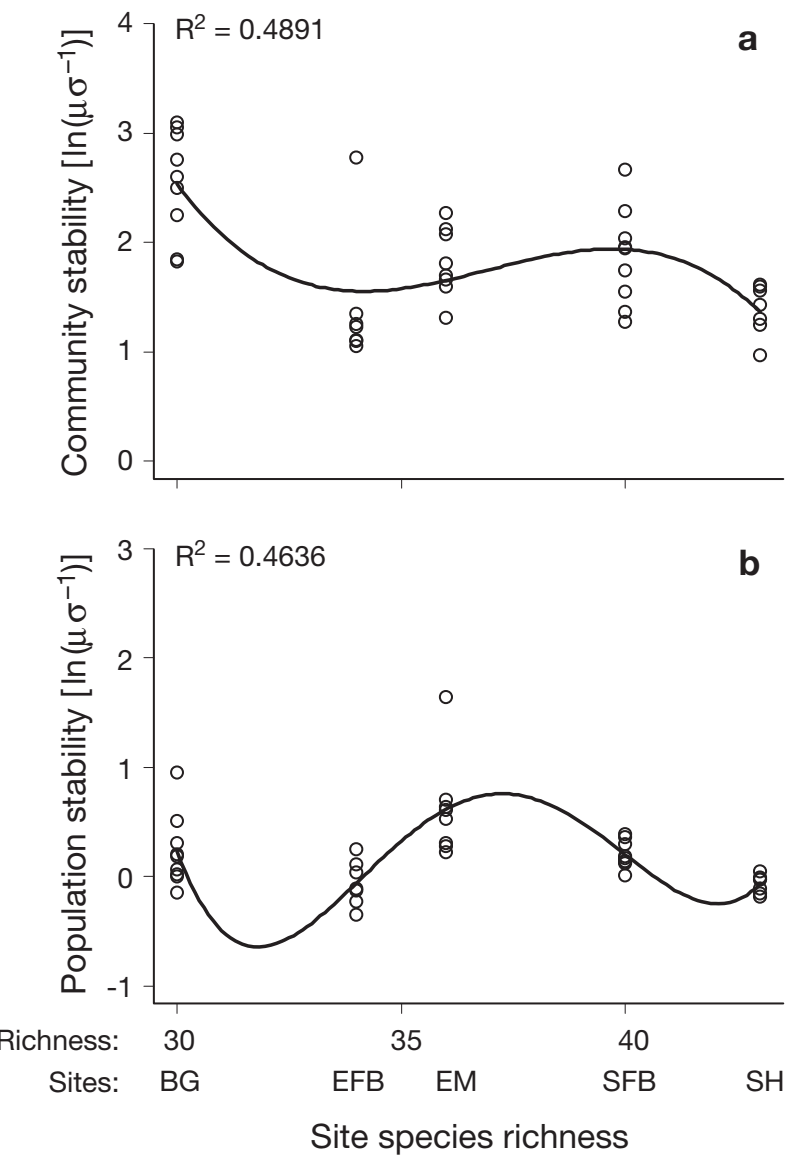

Fig. 1. Relationship between species richness and stability in percent coverage of epibenthic species. Stability was calculated as the quotient between the temporal mean in coverage, $\mu$, and its standard deviation, $\sigma$, over the same time period. (a) Stability of total community coverage. (b) Stability of coverage of single species averaged across 52 species. Each circle represents the stability of a $0.25 \mathrm{~m}^{2}$ plot that was followed over time. BG: barren ground; EFB: exposed Fucus bed; EM: exposed mole; SFB: semi-sheltered Fucus bed; SH: sheltered harbour. Regression parameters of site-specific species richness $(N)$ are: community stability $=227.25-18.53 N+0.50 N^{2}-$ $0.004 N^{3}$; population stability $=31450-346 N+14 N^{2}-0.25 N^{3}+$ $0.0017 N^{4}$

cant trend of increase (Fig. 2, Table 3). On the other hand, the summed covariances were independent of species richness (Fig. 2, Table 3). Summed covariances were on average $( \pm$ SEM) less than zero $(-766.2 \pm 188.5$, 1 -sample $t$-test, $\mathrm{p} \geq 0.001)$. When analysing each site separately, however, we found that summed covariances were less than zero at BG, EM and SH (1-sample $t$-tests, $\mathrm{p} \leq 0.03)$, but not at EFB and SFB (1-sample $t$-test, $\mathrm{p} \geq 0.09$ ). As a consequence of the insignificant relationship between the summed covariances and diversity, the net variance (i.e. summed variances plus summed covariances) followed a similar pattern to that of the summed variances, showing an irregular increase over the species richness gradient (Fig. 2, Table 3).
Table 2. Results of orthogonal polynomial regressions of species richness on community and population stability

\begin{tabular}{|lrrrr|}
\hline Source & df & MS & \multicolumn{1}{c|}{$F$} & $\mathrm{p}$ \\
\hline Community stability & & & & \\
Species richness, $N$ & 4 & 1.81 & 9.40 & $<0.0001$ \\
$\quad N_{\text {linear }}$ & 1 & 3.44 & 17.82 & 0.0002 \\
$N_{\text {quadratic }}$ & 1 & 0.79 & 4.08 & 0.0511 \\
$N_{\text {cubic }}$ & 1 & 2.63 & 13.61 & 0.0008 \\
$\quad N_{\text {quartic }}$ & 1 & 0.40 & 2.09 & 0.1569 \\
Residual & 35 & 0.19 & & \\
Population stability & & & & \\
Species richness, $N$ & 4 & 0.59 & 7.56 & 0.0002 \\
$\quad N_{\text {linear }}$ & 1 & 0.15 & 1.94 & 0.1725 \\
$N_{\text {quadratic }}$ & 1 & 0.48 & 6.17 & 0.0179 \\
$N_{\text {cubic }}$ & 1 & 0.30 & 3.89 & 0.0566 \\
$\quad N_{\text {quartic }}$ & 1 & 1.42 & 18.25 & 0.0001 \\
Residual & 35 & 0.08 & & \\
\hline & & & & \\
\hline
\end{tabular}

The fitted $z$-values $( \pm$ SEM) for the 3 taxa with the highest contributions to the within-site similarities were $1.26 \pm 0.14$ for Phymatolithon spp., $1.38 \pm 0.06$ for Fucus serratus, and $1.12 \pm 0.1$ for Cladophora rupestris; the fitted $z$-value for the entire data set was $1.34 \pm 0.01$. According to their $z$-values, the stability of these taxa should have decreased with species richness, but the individual regressions showed differing patterns. The stability of Phymatolithon spp. tended to decrease with increasing species richness, while that of F. serratus and $C$. rupestris showed large departures from linearity that resulted in a significant quartic fit for both species (Fig. 3, Table 4).

\section{DISCUSSION}

\section{Community stability}

Our observations suggest that community stability decreased as the number of species increased, in contrast to what most theoretical and empirical work predicts (reviewed by Hooper et al. 2005, Stachowicz et al. 2007). In addition, the patterns of community and population stability were highly complex. In the present study, the average total community coverage significantly increased with species richness (i.e. overyielding) and the variance scaled with the mean coverage with $1<z<2$. Overyielding and $z$-values between 1 and 2 should have led to a positive diversity-stability relationship (Tilman et al. 2006, van Ruijven \& Berendse 2007). Yet, increasing stability with increasing diversity also requires increasingly negative species covariances and an even distribution of species abundances.

On average, summed covariances were significantly less than zero. At both sites dominated by the canopy forming Fucus serratus, however, covariances were equal to or larger than zero. Positive covariances for 

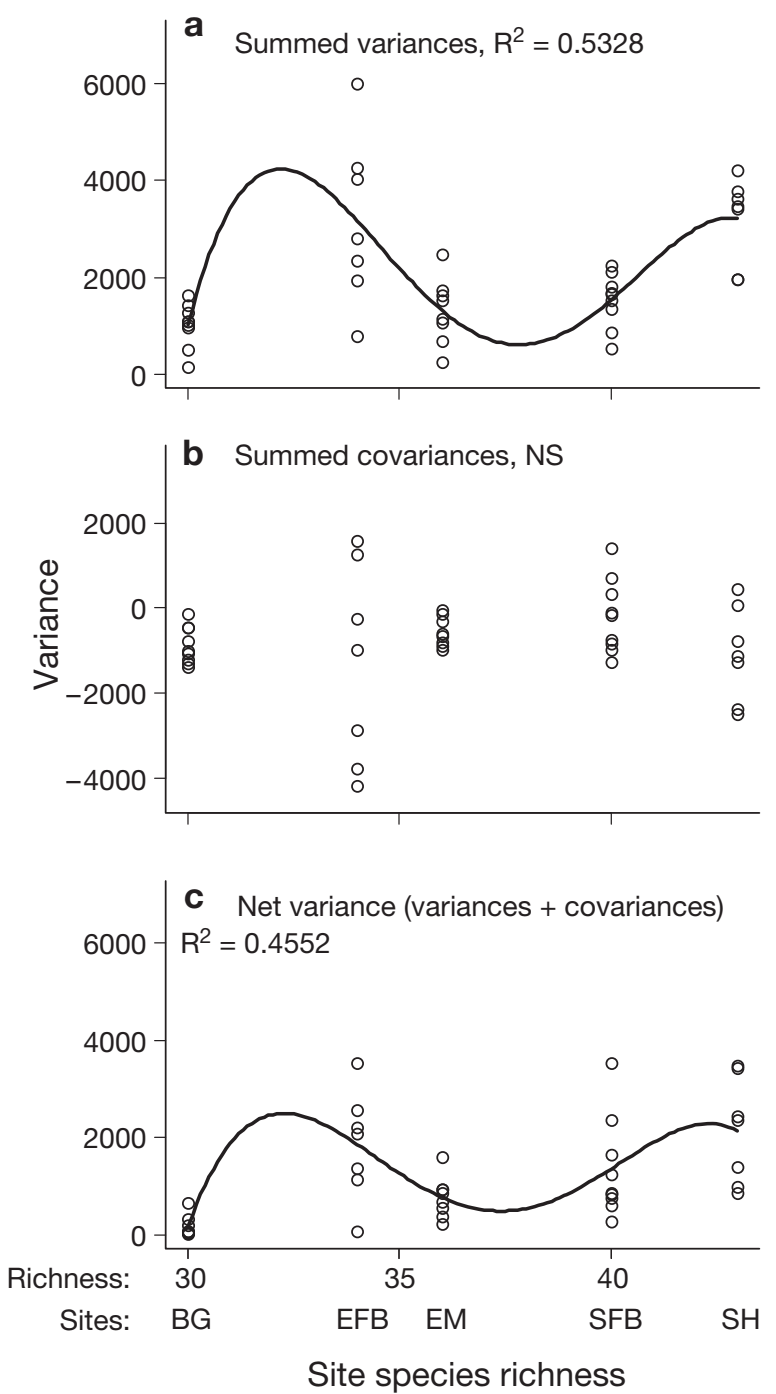

Fig. 2. Relationship between site-specific species richness and (a) summed variances, (b) summed covariances and (c) net variance (summed variances plus summed covariances). Site abbreviations as in Fig. 1. Regression parameters of sitespecific species richness $(N)$ are: summed variances $=$ $-7465000+810900 N-32790 N^{2}+585 N^{3}-4 N^{4} ;$ net variance $=$ $-5522000+602900 N-24530 N^{2}+441 N^{3}-3 N^{4}$

these sites may have resulted from the positive effect of F. serratus on obligate understorey species (N. Valdivia unpubl. data). Moreover, persistent removals of the $F$. serratus canopy caused compensatory dynamics of species with different environmental tolerances; the resulting negative covariances buffered the community stability but reduced the population stability (N. Valdivia unpubl. data). Therefore, the covariance in the species responses to environmental disturbances can strongly influence the stability of the shores studied here. In the present study, the insignificant relationship between species covariances and species richness probably prevented a positive effect of diversity on stability.
Table 3. Results of orthogonal polynomial regressions of species richness on summed variances, summed covariances and net variance (summed variances + summed covariances)

\begin{tabular}{|lrrrr|}
\hline Source & df & \multicolumn{1}{c}{ MS } & \multicolumn{1}{c|}{$F$} & \multicolumn{1}{c|}{$\mathrm{p}$} \\
\hline Summed variances & & & & \\
Species richness, $N$ & 4 & 8490828 & 9.98 & $<0.0001$ \\
$\quad N_{\text {linear }}$ & 1 & 7589923 & 8.92 & 0.0051 \\
$N_{\text {quadratic }}$ & 1 & 142765 & 0.17 & 0.6846 \\
$N_{\text {cubic }}$ & 1 & 19102565 & 22.45 & $<0.0001$ \\
$N_{\text {quartic }}$ & 1 & 7128060 & 8.38 & 0.0065 \\
Residual & 35 & 850863 & & \\
Summed covariances & & & & \\
Species richness, $N$ & 4 & 1564017 & 1.11 & 0.3662 \\
$N_{\text {linear }}$ & 1 & 426974 & 0.30 & 0.5851 \\
$N_{\text {quadratic }}$ & 1 & 555457 & 0.40 & 0.5337 \\
$N_{\text {cubic }}$ & 1 & 4858397 & 3.46 & 0.0715 \\
$N_{\text {quartic }}$ & 1 & 415240 & 0.30 & 0.5902 \\
Residual & 35 & 1405830 & & \\
Net variance (summed variances + summed covariances) \\
Species richness, $N$ & 4 & 5137088 & 7.31 & 0.0002 \\
$N_{\text {linear }}$ & 1 & 11617286 & 16.54 & 0.0003 \\
$N_{\text {quadratic }}$ & 1 & 135017 & 0.19 & 0.6638 \\
$N_{\text {cubic }}$ & 1 & 4693597 & 6.68 & 0.0141 \\
$N_{\text {quartic }}$ & 1 & 4102454 & 5.84 & 0.0210 \\
Residual & 35 & 702542 & & \\
\hline
\end{tabular}

The relationship between species richness and stability was also influenced by the relative abundance of species. In this experiment, 3 taxa explained ca. $60 \%$ of the sum of all of the species coverage values. When few taxa numerically dominate the system, community stability can be driven by fluctuations of these components (Steiner et al. 2005, Polley et al. 2007). In addition, large differences among species abundances can result in negative and curvilinear richness-stability relationships when $z=1.2$ (Lhomme \& Winkel 2002). In our case, the $z$-values were close to 1.2 (e.g. $1.26 \pm 0.14$ for Phymatolithon spp., but $1.35 \pm 0.01$ for all species), suggesting that large heterogeneity among species abundances may also explain the negative and complex pattern of community stability.

Overyielding probably resulted from the multilayered structure of macrobenthic assemblages, which allows single species to expand by differential use of the available space. Erect life forms use little space of primary substratum, but can expand above the substratum and thus increase in abundance. This leads, in some cases, to a total percent coverage of $>100$. For instance, seaweeds can develop and expand a canopy in an area where the primary substratum is monopolised by encrusting forms (Connell 2003). Such a spatial structure was apparent in the present study, as encrusting, turfing, and canopy-forming algae formed 3 layers of biota. This suggests that if we had focused on 1 layer of species (i.e. had not allowed total percent coverage values $>100$ ), we probably would not have found overyielding. On the other hand, large spatial 

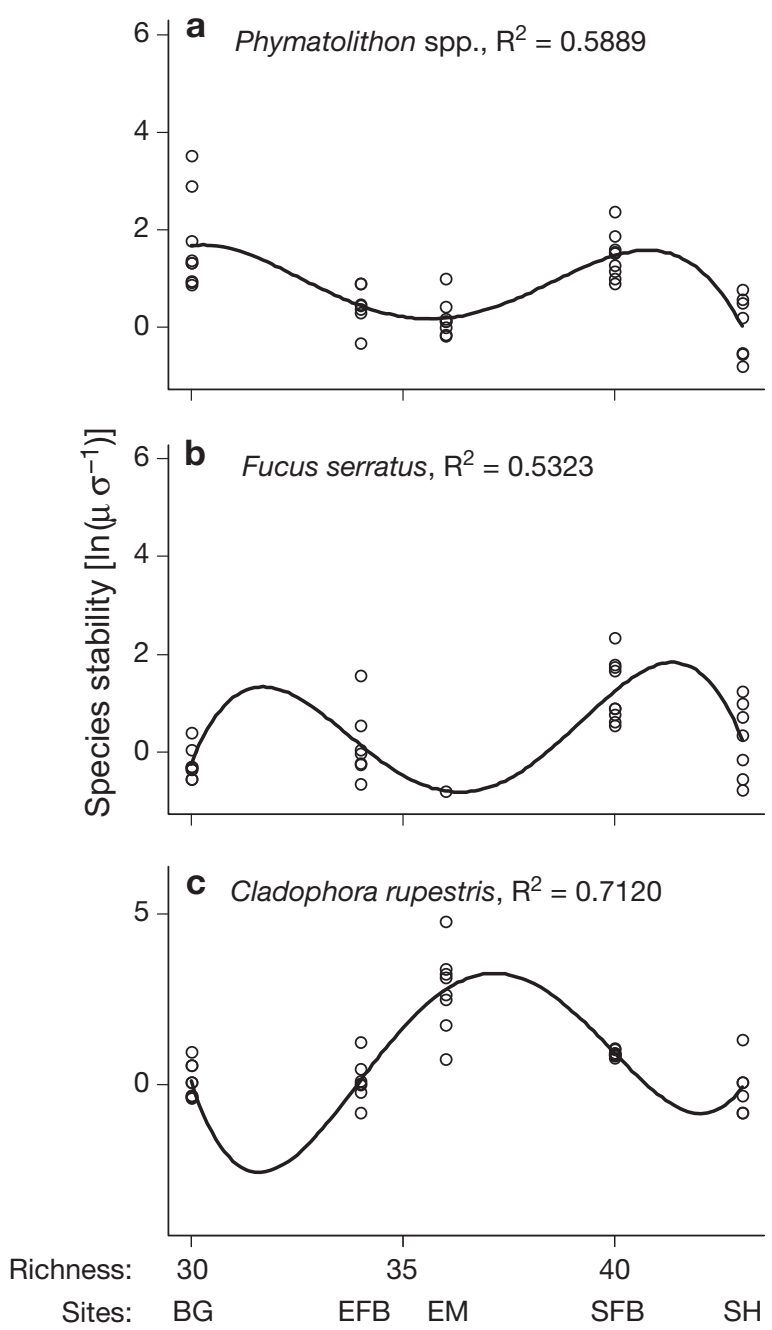

Site species richness

Fig. 3. Patterns of stability in percent coverage of the 3 taxa with the highest and most consistent contributions to the within-site similarities. Site abbreviations as in Fig. 1. Regression parameters of site-specific species richness $(N)$ on stability $(S)$ are as follows: $S_{\text {Phymatolithon spp. }}=-3014+346.5 \mathrm{~N}-$ $14.83 N^{2}+0.27 N^{3}-0.002 N^{4} ; S_{\text {Fucus serratus }}=-7531+841 N-$ $0.35 N^{2}+0.6 N^{3}-0.004 N^{4} ; S_{\text {Cladophora rupestris }}=1980-1324 N+$ $54.51 N^{2}-0.9 N^{3}+0.007 N^{4}$

structures may also have caused community stability to decrease with species richness, because such structures create refuges and increase the probability of survival in communities dominated by a few species (Dunstan \& Johnson 2004, 2006).

\section{Population stability}

We detected significant fluctuations in the pattern of population stability across the species richness gradient, but we did not find a clear trend of decreasing values. Population stability should decrease with increas-
Table 4. Results of orthogonal polynomial regressions of species richness on the stability of each of the 3 dominant taxa

\begin{tabular}{|lrrrr|}
\hline Source & df & \multicolumn{1}{c}{ MS } & \multicolumn{1}{c|}{$F$} & \multicolumn{1}{c|}{$\mathrm{p}$} \\
\hline Phymatolithon spp. & & & & \\
Species richness, $N$ & 4 & 4.70 & 12.54 & $<0.0001$ \\
$N_{\text {linear }}$ & 1 & 3.75 & 10.00 & 0.0032 \\
$N_{\text {quadratic }}$ & 1 & 1.14 & 3.03 & 0.0904 \\
$N_{\text {cubic }}$ & 1 & 12.09 & 32.25 & $<0.0001$ \\
$N_{\text {quartic }}$ & 1 & 1.82 & 4.86 & 0.0341 \\
Residual & 35 & 0.37 & & \\
Fucus serratus & & & & \\
Species richness, $N$ & 4 & 3.05 & 7.97 & 0.0002 \\
$N_{\text {linear }}$ & 1 & 4.88 & 12.72 & 0.0013 \\
$N_{\text {quadratic }}$ & 1 & 1.83 & 4.79 & 0.0372 \\
$N_{\text {cubic }}$ & 1 & 3.53 & 9.22 & 0.0051 \\
$N_{\text {quartic }}$ & 1 & 1.97 & 5.15 & 0.0312 \\
Residual & 28 & 0.38 & & \\
Cladophora rupestris $_{\text {sis }}$ & & & & \\
Species richness, $N$ & 4 & 10.88 & 21.02 & $<0.0001$ \\
$N_{\text {linear }}$ & 1 & 0.28 & 0.54 & 0.4659 \\
$N_{\text {quadratic }}$ & 1 & 20.80 & 40.19 & $<0.0001$ \\
$N_{\text {cubic }}$ & 1 & 1.30 & 2.51 & 0.1225 \\
$N_{\text {quartic }}$ & 1 & 21.14 & 40.84 & $<0.0001$ \\
Residual & 34 & 0.52 & & \\
& & & & \\
\hline
\end{tabular}

ing diversity if the latter is positively related to the number of potential competitive interactions or to the variety of adaptive responses to the environment (Ives et al. 2000). In the present study, the absence of a negative diversity-covariance relationship suggests that both the variety of environmental tolerances and the number of competitive interactions were independent of diversity. The differential use of space could have alleviated competition at high-diversity sites, reducing the probability of compensatory changes that cause individual populations to be more variable.

According to their $z$-values, the stability of single species should have decreased with species richness (Tilman 1999). However, individual species tended to be more stable at sites where they were more abundant. Similarly, a recent experiment in which species abundances varied across the diversity gradient showed that the stability of single species performed differently than expected based on variance-mean rescaling (van Ruijven \& Berendse 2007). Because constancy in species abundance is an assumption of statistical averaging (Doak et al. 1998), this mechanism may be well supported by manipulative experiments, but probably not by observational studies.

Our observations agree with studies conducted in multitrophic systems, showing no clear diversity effect on population stability (McGrady-Steed \& Morin 2000, Steiner et al. 2005), but they contradict studies conducted on single trophic levels that show negative relationships (Tilman et al. 2006, van Ruijven \& Berendse 2007). In our case, primary producers domi- 
nated the assemblages in terms of abundance, but $57 \%$ of the taxa were invertebrates. On the other hand, keystone consumers can strongly control the community structure (Paine 1966). Therefore, the high stability of Phymatolithon spp. at the species-poor BG site might be related to the large density of the periwinkle Littorina littorea observed at the study site. Epibenthic grazers like L. littorea control the recruitment of algae, thereby affecting the structure of macrobenthic assemblages (McQuaid 1996). The grazing activity of L. littorea at BG may be an important factor in depressing species richness and simultaneously promoting the persistence of encrusting algae like Phymatolithon spp. at high abundances. Manipulative experiments are necessary to address the role of trophic interactions on the relationship between diversity and stability.

In conclusion, we observed a negative and curvilinear pattern in community stability and a complex pattern in population stability. Probably, putative positive effects of overyielding and variance-mean rescaling on community stability were offset by strong heterogeneity among species abundances and invariant species covariances across the species richness gradient. The observational evidence presented here is not unequivocal, since we did not control for factors that might have covaried with species richness, such as wave exposure or nutrient levels. In addition, ecosystem properties such as fluxes of nutrients and carbon were not assessed. Because different ecosystem properties can have different responses to changes in diversity (Jiang et al. 2008), experiments that explore multiple ecosystem properties may provide a more comprehensive view of the functional role of diversity. Nevertheless, we still suggest that the relative abundance of species and ecological interactions influencing the covariances among species may play a pivotal role in the relationship between diversity and ecosystem stability.

Acknowledgements. We are grateful to a number of friends and colleagues who enthusiastically helped during long hours of field work, including J. Ellrich, A. Engel, M. Honens, J. Karkosz, M. Marklewitz, A. Wagner, and H. Y. Yun. A. Knox polished the language of an early version of the manuscript. This work forms part of the MarBEF responsive model project BIOFUSE. Financial support by the Alfred-Wegener-Institute for Marine and Polar Research to N.V. is acknowledged.

\section{LITERATURE CITED}

Bartsch I, Tittley I (2004) The rocky intertidal biotopes of Helgoland: present and past. Helgol Mar Res 58:289-302

Clarke KR, Warwick RM (2001) Change in marine communities: an approach to statistical analysis and interpretation. PRIMER-E Ltd, Plymouth

Connell SD (2003) The monopolization of understorey habitat by subtidal encrusting coralline algae: a test of the com- bined effects of canopy-mediated light and sedimentation. Mar Biol 142:1065-1071

Cottingham KL, Brown BL, Lennon JT (2001) Biodiversity may regulate the temporal variability of ecological systems. Ecol Lett 4:72-85

Doak DF, Bigger D, Harding EK, Marvier MA, O'Malley RE, Thomson D (1998) The statistical inevitability of stabilitydiversity relationships in community ecology. Am Nat 151: 264-276

Dunstan PK, Johnson CR (2004) Invasion rates increase with species richness in a marine epibenthic community by two mechanisms. Oecologia 138:285-292

Dunstan PK, Johnson CR (2006) Linking richness, community variability, and invasion resistance with patch size. Ecology $87: 2842-2850$

Elton SC (1958) The ecology of invasions by animals and plants. The University of Chicago Press, Chicago, IL

Gessner MO, Inchausti P, Persson L, Raffaelli DG, Giller PS (2004) Biodiversity effects on ecosystem functioning: insights from aquatic systems. Oikos 104:419-422

Giller PS, Hillebrand H, Berninger UG, Gessner MO and others (2004) Biodiversity effects on ecosystem functioning: emerging issues and their experimental test in aquatic environments. Oikos 104:423-436

> Hector A, Schmid B, Beierkuhnlein C, Caldeira MC and others (1999) Plant diversity and productivity experiments in European grasslands. Science 286:1123-1127

Hooper DU, Chapin III, FS, Ewel JJ, Hector A and others (2005) Effects of biodiversity on ecosystem functioning: a consensus of current knowledge. Ecol Monogr 75:3-35

Ives AR, Klug JL, Gross K (2000) Stability and species richness in complex communities. Ecol Lett 3:399-411

Jiang L, Pu Z, Nemergut DR (2008) On the importance of the negative selection effect for the relationship between biodiversity and ecosystem functioning. Oikos 117 : 488-493

Johnson KH, Vogt KA, Clark H, Schmitz O, Vogt D (1996) Biodiversity and the productivity and stability of ecosystems. Trends Ecol Evol 11:372-377

Lehman CL, Tilman D (2000) Biodiversity, stability, and productivity in competitive communities. Am Nat 156:534-552

Lhomme JP, Winkel T (2002) Diversity-stability relationships in community ecology: re-examination of the portfolio effect. Theor Popul Biol 62:271-279

> Loreau M, Hector A (2001) Partitioning selection and complementarity in biodiversity experiments. Nature 412:72-76

> MacArthur RH (1955) Fluctuations of animal populations and a measure of community stability. Ecology 36:533-536

McGrady-Steed J, Morin PJ (2000) Biodiversity, density compensation, and the dynamics of populations and functional groups. Ecology 81:361-373

McQuaid CD (1996) Biology of the gastropod family Littorinidae. II. Role in the ecology of intertidal and shallow marine ecosystems. Oceanogr Mar Biol Annu Rev 34: 263-302

- Paine R (1966) Food web complexity and species diversity. Am Nat 100:65-75

Polley HW, Wilsey BJ, Derner JD (2007) Dominant species constrain effects of species diversity on temporal variability in biomass production of tallgrass prairie. Oikos 116: 2044-2052

R Development Core Team (2008) R: a language and environment for statistical computing. R Foundation for Statistical Computing, Vienna

Shea K, Chesson P (2002) Community ecology theory as a framework for biological invasions. Trends Ecol Evol 17: $170-176$ 
Sokal RR, Rohlf RJ (1995) Biometry. Freeman and Company, New York

Stachowicz JJ, Bruno JF, Duffy JE (2007) Understanding the effects of marine biodiversity on communities and ecosystems. Annu Rev Ecol Evol Syst 38:739-766

Steiner CF, Long ZT, Krumins JA, Morin PJ (2005) Temporal stability of aquatic food webs: partitioning the effects of species diversity, species composition and enrichment. Ecol Lett 8:819-828

Taylor LR (1961) Aggregation, variance and the mean. Nature 189:732-735

Tilman D (1996) Biodiversity: population versus ecosystem stability. Ecology 77:350-363

Tilman D (1999) The ecological consequences of changes in biodiversity: a search for general principles. Ecology 80 : 1455-1474

Tilman D, Lehman CL, Thomson KT (1997) Plant diversity and ecosystem productivity: theoretical considerations. Proc

Editorial responsibility: Sean Connell,

Adelaide, Australia
Natl Acad Sci USA 94:1857-1861

> Tilman D, Lehman CL, Bristow CE (1998) Diversity-stability relationships: Statistical inevitability or ecological consequence? Am Nat 151:277-282

Tilman D, Reich PB, Knops JMH (2006) Biodiversity and ecosystem stability in a decade-long grassland experiment. Nature 441:629-632

van Ruijven J, Berendse F (2007) Contrasting effects of diversity on the temporal stability of plant populations. Oikos 116:1323-1330

Vasseur DA, Gaedke U (2007) Spectral analysis unmasks synchronous and compensatory dynamics in plankton communities. Ecology 88:2058-2071

Walker BH (1992) Biodiversity and ecological redundancy. Conserv Biol 6:18-23

Yachi S, Loreau M (1999) Biodiversity and ecosystem productivity in a fluctuating environment: the insurance hypothesis. Proc Natl Acad Sci USA 96:1463-1468

Submitted: August 7, 2008; Accepted: November 18, 2008 Proofs received from author(s): January 12, 2009 